\section{Dement Geriatr Cogn Disord Extra 2011;1:318-329}

DOI: $10.1159 / 000333080$

(c) 2011 S. Karger AG, Basel

Published online: October 20, 2011

www.karger.com/dee NonCommercial-NoDerivs 3.0 License (www.karger.com/OA-license), applicable to the online version of the article only. Distribution for non-commercial purposes only.

Original Research Article

\title{
Long Latency and High Variability in Accuracy-Speed of Prosaccades in Alzheimer's Disease at Mild to Moderate Stage
}

\author{
Qing Yang ${ }^{\mathrm{a}}$ Tao Wang $^{\mathrm{b}}$ Ning Su $^{\mathrm{b}}$ Yuanyuan Liu ${ }^{\mathrm{b}}$ \\ Shifu Xiao ${ }^{b}$ Zoi Kapoula ${ }^{a}$ \\ aIRIS Group, UMR 8194, CNRS, Hôpital Européen Georges Pompidou, Paris, France; \\ ${ }^{\mathrm{b}}$ Geriatric Psychiatry Department, Shanghai Mental Health Center, Shanghai Jiaotong \\ University School of Medicine, Shanghai, China
}

\section{Key Words}

Alzheimer's disease · Gap · Mild cognitive impairment · Overlap · Saccades · Variability

\begin{abstract}
Background: Studying saccades is a useful tool to investigate brain function. There is still controversy regarding deficits in prosaccades in Alzheimer's disease (AD), and a study of saccades in subjects with mild cognitive impairment $(\mathrm{MCl})$ has not been published to date. Methods: We examined horizontal saccades in 10 healthy elderly, and $9 \mathrm{MCl}$ and $9 \mathrm{AD}$ patients. Two tasks were used: gap (fixation target extinguishes prior to target onset) and overlap (fixation stays on after target onset). Eye movements were recorded with the Skalar IRIS system. Results: (1) Latencies were shorter in the gap than in the overlap task (a gap effect) in all three groups of subjects: healthy elderly, MCl and AD; (2) for both tasks, latency of saccades was longer for AD patients than for healthy and $\mathrm{MCl}$ subjects, and (3) accuracy and mean velocity were normal in $\mathrm{MCl}$ and $A D$ subjects, however, variability in accuracy-speed was higher for AD patients than for healthy and $\mathrm{MCl}$ subjects in the overlap task. Conclusions: Abnormalities in reaction time and accuracyspeed variability reflect deficits in cerebral areas involved in the triggering and execution of saccades; a saccade test can be useful to follow up the evolution of $\mathrm{MCl}$ subjects as some of them may develop AD disease.

Copyright $\odot 2011$ S. Karger AG, Basel
\end{abstract}

Q.Y., S.X. and Z.K. contributed equally to this work. 


\section{Introduction}

Alzheimer's disease (AD) is the most common form of dementia, accounting for $50-70 \%$ of dementia cases [1]. In early-stage AD, memory and cognitive loss is mild, but at late-stage $\mathrm{AD}$, individuals lose the ability to carry on a conversation and respond to their environment. Therefore, early diagnosis, simple tools for progression monitoring and even therapy response measures are very important in the management of AD. Recently, studies in subjects with mild cognitive impairment (MCI) have become prominent as persons with this mild dysfunction are at high risk for the future development of AD [2]. About 10-15\% of MCI subjects will progress to $\mathrm{AD}$ within 1 year, a rate which is markedly higher than in a normal elderly population [3-5]. Therefore, the identification of early and objective evaluation of MCI as well as factors indicating prognosis are of importance.

Saccade, particularly prosaccade, is the type of eye movement to be evoked without effort for any subject, including elderly. Most studies showed that AD patients have impaired inhibitory control and error correction in antisaccades, which exceeds the effects of normal aging and is related to the severity of dementia. Yet, antisaccades are a difficult task for elderly, especially for patients with dementia. Compared with antisaccades, prosaccades seem to be more easily executed for AD patients. However, till now there are still controversial results on deficits in prosaccades in $\mathrm{AD}$ patients. Abnormal long latencies of prosaccades were reported in many studies [6-12]. In these studies, the mean age of AD patients ranged from 58 to 78 years and their mean score in Mini Mental State Examination (MMSE) from 17 to 21. In addition, different studies use stimulus eccentricities from 3 to $20^{\circ}$ and numbers for AD subjects are from 11 to 35 . Yet, two other studies $[13,14]$ reported that AD patients had no significant impairment in prosaccades. The mean age of their AD patients was 69-78 years, their mean MMSE 17.9-20.6, stimulus eccentricities were from 15 to $16^{\circ}$ and the numbers of $\mathrm{AD}$ patients were 11 and 22, respectively. All these factors were similar in the two study groups with different results. Therefore, experimental conditions cannot account for such controversial results in the literature.

Variability in the saccade latency increases with age [24-26]. The increase in variability of saccade latency can point to particular neural deficits in the patients $[15,16]$. For instance, Blekher et al. [16] reported that patients with Huntington's disease demonstrated an increased error rate, increased mean latency and increased variability in latency for memoryguided saccades and antisaccades. Kapoula et al. [27] showed increased variability in all parameters of saccades in patients with Lewy body dementia. Variability in saccade latency and speed-accuracy parameters has not yet been examined in AD and MCI patients.

For accuracy-speed deficits in AD patients, experimental evidence is also controversial. Some studies reported lower gain and lower velocity $[6,8,17]$, while other studies $[9,11]$ did not demonstrate differences in prosaccade gain and velocity between healthy elderly and AD patients. Whether saccade accuracy and speed are subject to aging is also controversial. A few studies described a reduction in velocity in normal elderly compared to young subjects $[18,19]$. Yet, these reductions in velocity were most evident with large amplitude saccades, usually to targets beyond $20^{\circ}$ eccentricity. Note that in another study [20], no aging effects were observed either on accuracy or on velocity (for target at $20^{\circ}$ of eccentricity). Our study of vertical saccades [21] demonstrated no effects of aging on accuracy.

To summarize, there is controversy over the existence of saccade deficits in $\mathrm{AD}$ patients in simple prosaccade tasks (although the majority of existing studies suggest deficits in latencies), while no studies exist in MCI subjects. However, there are some investigations on the cognitive functions using reaction time in MCI. For both simple reaction time and choice reaction time, no significant difference was found between control and MCI subjects [2, 22-24]. In these studies, MCI subjects had mean MMSE scores similar to controls. 
Table 1. Demographics of the study cohort

\begin{tabular}{lccc}
\hline & Controls & MCI & AD \\
\hline Subjects, $\mathrm{n}$ & 10 & 9 & 9 \\
Age, years & $69.7 \pm 6.1$ & $71.4 \pm 9.8$ & $68.7 \pm 9.2$ \\
Gender, males/females & $6 / 4$ & $6 / 3$ & $4 / 5$ \\
Education, years & $10.4 \pm 3.6$ & $13.2 \pm 2.8$ & $10.3 \pm 2.6$ \\
MMSE & 30 & $25.9 \pm 1.2$ & $16.9 \pm 3.4$ \\
Activities of daily living (max. 56) & 14 & $15.0 \pm 1.3$ & $36.3 \pm 6.6$ \\
Estimated duration of disease, years & - & $2.0 \pm 0.8$ & $2.7 \pm 1.3$ \\
\hline
\end{tabular}

The goal of this study was to compare latency, accuracy and speed of prosaccades in gap and overlap tasks between subjects with MCI and patients with $\mathrm{AD}$ at moderate stage with age-matched healthy elderly.

\section{Patients and Methods}

\section{Participants}

We studied normal elderly controls, patients with amnestic MCI and Alzheimer's disease $(\mathrm{AD})$ of mild to moderate severity, without ophthalmological or other neuropsychiatric disorders. All subjects had normal, or corrected to normal, visual acuity without group difference by age or gender. MCI and AD patients were recruited from the Department of Geriatric Psychiatry in the Shanghai Mental Healthy Center. Spouses of amnestic MCI or AD patients were recruited as control elderly. AD was diagnosed according to DSM-IV criteria and MCI according to modifications of Petersen's criteria [3-5, 25, 26]. The MMSE [27] was used as a gold standard screening measure to diagnose and determine the severity of overall cognitive decline in cases of MCI or AD.

Participants consisted of 9 individuals ( 4 men) with AD (ranging from 57 to 81 years, mean $68.7 \pm 9.2$ years); MMSE ranged from 13 to 22 (mean $16.9 \pm 3.4$ ). There were 9 subjects (6 men) with MCI (age range: $59-84$ years, mean $71.4 \pm 9.5$ years) and their MMSE scores were from 24 to $28(25.9 \pm 1.2)$. Ten healthy subjects ( 6 men, matched for age and education to MCI or AD subjects) with an MMSE score of 30, aged 62-80 years (mean 69.7 \pm 6.1 years), were also studied. All clinical characteristics of the study participants are summarized in table 1. Informed consent was obtained from all participants, and the study was approved by the Institutional Review Board of the Shanghai Mental Health Center.

\section{Visual Display}

Visual display (fig. 1a) was composed of three white luminous dots (angular size $0.4^{\circ}$ ) presented on a black computer screen. One of these three dots was at the center of the screen, two were at an eccentricity of $\pm 10^{\circ}$ horizontally. The subject was comfortably seated in an adapted chair, with his head resting on his/her chin and frontal support. The subject viewed binocularly; all dots were highly visible.

\section{Fixation and Oculomotor Tasks: Gap and Overlap Tasks}

Each trial started by lighting a fixation dot at the center. The fixation dot stayed on for a random period of 1.5-2 s. In the gap task, there was a time interval of $200 \mathrm{~ms}$ between the offset of the fixation point and the onset of the saccade target. The target dot was kept for 
Fig. 1. Experimental design. a Spatial arrangement: 3 white luminous dots (angular size $0.2^{\circ}$ ) were presented on a black computer screen $57 \mathrm{~cm}$ from the subject, one at the center of the screen and the others at an eccentricity of $\pm 10^{\circ}$ horizontally or vertically. b, c Temporal arrangement. Each trial started by lighting one central dot during approximately 1,500-2,000 ms. For the gap task, between the fixation offset and the target onset, there was a gap of $200 \mathrm{~ms}$ (b); for the overlap task, the fixation stayed on $200 \mathrm{~ms}$ after the target onset (c). The target, one of the eccentric dots, appeared for $1,500 \mathrm{~ms}$.
Yang et al.: Saccades in AD and MCI

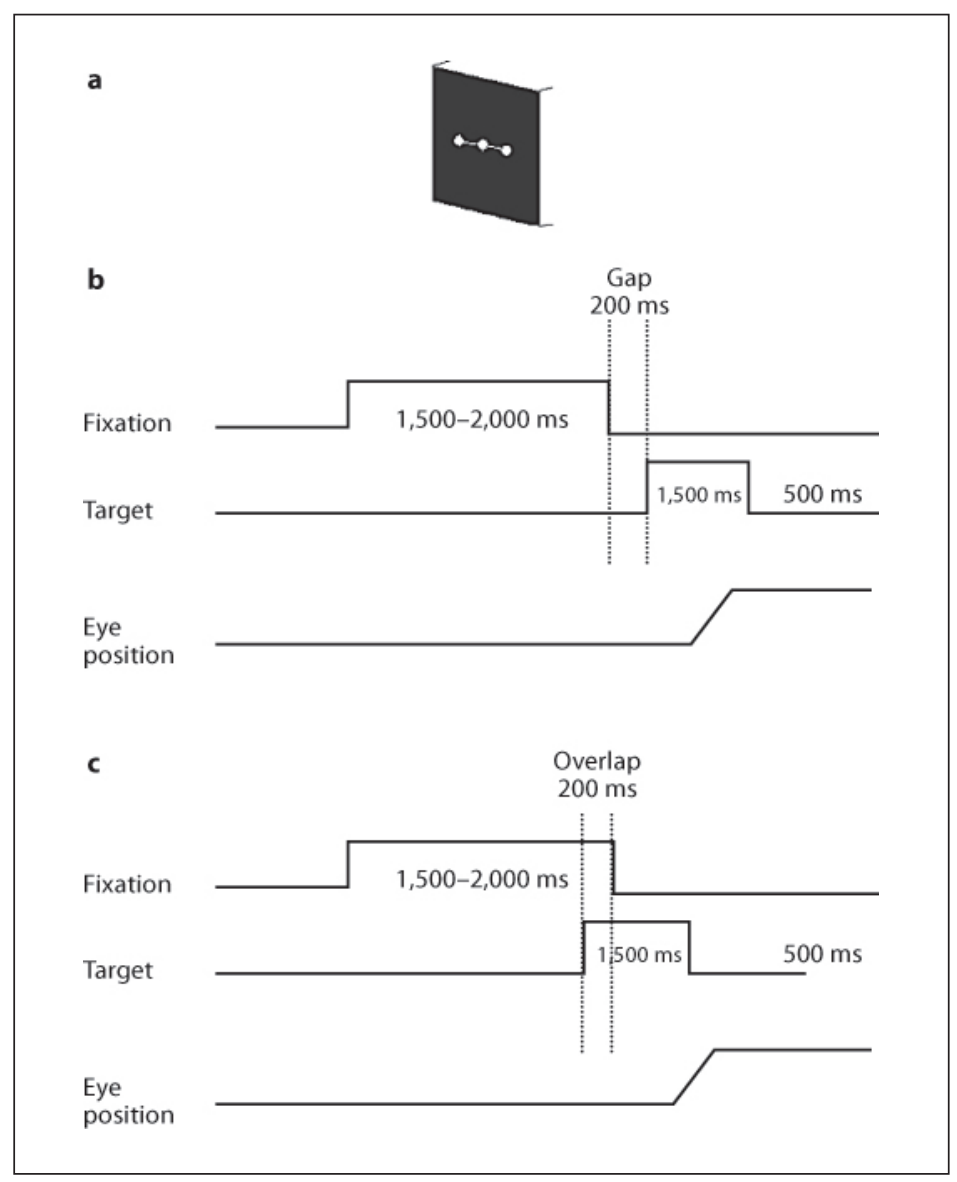

$1.5 \mathrm{~s}$ (fig. 1b). In the overlap task, the fixation point remained illuminated for $200 \mathrm{~ms}$ after the target dot appeared. The target also stayed on for another $1.5 \mathrm{~s}$ (fig. 1c). Subjects were required to make a saccade to the target point as rapidly and accurately as possible. The break consisted of a period of complete darkness for $500 \mathrm{~ms}$. Subjects were instructed to use this period for blinks. The total mean length of each trial was about $4 \mathrm{~s}$. In each block, only gap or overlap tasks were used randomly for two horizontal directions: targets at $10^{\circ}$ left or right (15 trails for each direction, total 30 trials). One block for each task lasted $2.5 \mathrm{~min}$.

A calibration sequence was performed at the beginning; the target made the following predictive sequence: center, $10^{\circ}$ to the left, center, $10^{\circ}$ to the right, four times; the target stayed at each location for $2 \mathrm{~s}$. From these recordings, we extracted calibration factors.

\section{Eye Movement Recording}

Horizontal eye movements were recorded binocularly with an infrared eye movement device (IRIS; Skalar, Delft, The Netherlands). Eye position signals were low-pass filtered with a cutoff frequency of $200 \mathrm{~Hz}$ and were digitized with a 12-bit analog-to-digital converter, and each channel was sampled at $500 \mathrm{~Hz}$. The optimal resolution was approximately $0.1^{\circ}$.

\section{Data Analysis}

From the two individual calibrated eye position signals, we derived the conjugate signal (left eye + right eye)/2. The onset and the offset of saccades were defined as the time when conjugate eye velocity exceeded or dropped below $10 \%$ of the peak velocity. The process was 
Fig. 2. Typical recordings of horizontal saccades are obtained by averaging the position signal of the two eyes (left eye + right eye) $/ 2$ and their corresponding velocity traces for 1 healthy elderly. The arrows ' $i$ ' and ' $e$ ' indicate the onset and the end of the primary saccade, respectively.

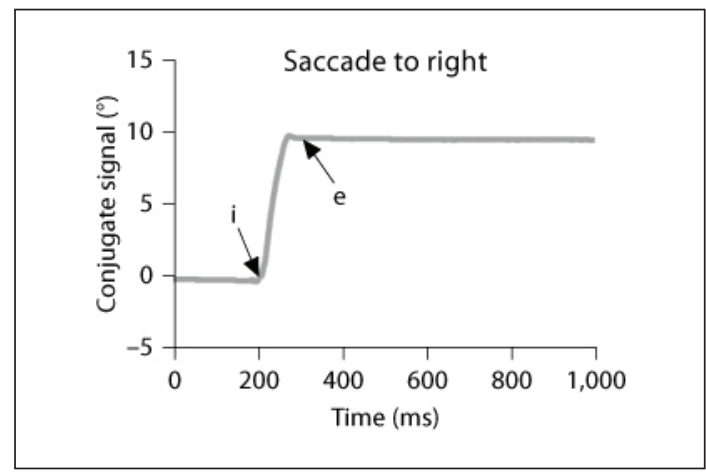

performed automatically by the computer, and the verification was made by visual inspection of the individual eye position and velocity traces. For both gap and overlap tasks, latency was measured as the time between target onset (time 0) and saccade onset (mark ' $i$ ' in fig. 2). To estimate the accuracy, we used the amplitude of the primary main saccade (between ' $i$ ' and ' $e$ ') relative to the target eccentricity (gain = saccade amplitude/target eccentricity). Mean velocity was calculated as amplitude/duration (time between ' $i$ ' and ' $e$ '). To evaluate the variability in parameters, we calculated the coefficient of variation (CV), the relative standard deviation expressed as a unitless proportion of each subject mean [28, 29].

Eye movements in the wrong direction, with latency $<80 \mathrm{~ms}$ (anticipation) or $>1,500 \mathrm{~ms}$, or contaminated by blinks were rejected. For healthy elderly, 7\% of trials (range: 5-10\%), for MCI subjects $6 \%$ of trials (range: 4-9\%) and for patients with AD 15\% of trials (range: $5-25 \%$ ) had to be rejected, the most frequent reason being the blinks.

\section{Statistical Analysis}

A three-way analysis of variance (ANOVA) was performed on individual mean values of each parameter with the between-subject factor - group (healthy, MCI and AD) - and the within-subject factors - the oculomotor task (gap/overlap) and the direction (left/right). Post hoc comparisons were done with the least-significant-difference test. For the coefficient of variation of each parameter, the non-parametric Kruskal-Wallis and the Mann-Whitney U test were used for comparisons between groups; for within-subject comparisons between different directions or tasks, the Wilcoxon test was used.

\section{Results}

\section{Latency}

Mean Latency. Figures 3 and 4 show individual latency (+ SE) for leftward and rightward saccades in healthy elderly, MCI and AD subjects for the gap and overlap tasks, respectively. The numbers on the horizontal axis represent MMSE scores and age for each subject. Threeway ANOVA showed a gap effect, i.e. significantly shorter latencies for gap than for overlap tasks $\left(\mathrm{F}_{1,25}=48.3, \mathrm{p}<0.01\right)$, but no direction effect $\left(\mathrm{F}_{1,25}=0.8, \mathrm{p}=0.37\right)$; there was a group effect, i.e. significantly longer latencies for patients with $\mathrm{AD}$ than for healthy elderly and $\mathrm{MCI}$ $\left(\mathrm{F}_{2,25}=7.2, \mathrm{p}<0.01\right)$. Further post hoc comparisons showed that the gap effect was significant for all three groups of subjects and for both directions (all $p<0.001$ ). The mean values of the gap effect were 95, 86 and $160 \mathrm{~ms}$ for healthy elderly, MCI and AD subjects, respectively. The group effect was significant for both gap and overlap tasks, and for both directions (all p $<0.05$ ). 
Fig. 3. Individual and group mean latencies of saccades (+ SE) in the gap task for leftward and rightward saccades in healthy elderly (a), in subjects with MCI (b) and in patients with $\mathrm{AD}$ (c); horizontal axes represent MMSE score and age for each subject. Note: longer latencies of saccades for $\mathrm{AD}$ patients than for healthy elderly and MCI subjects for each direction.
Yang et al.: Saccades in AD and MCI

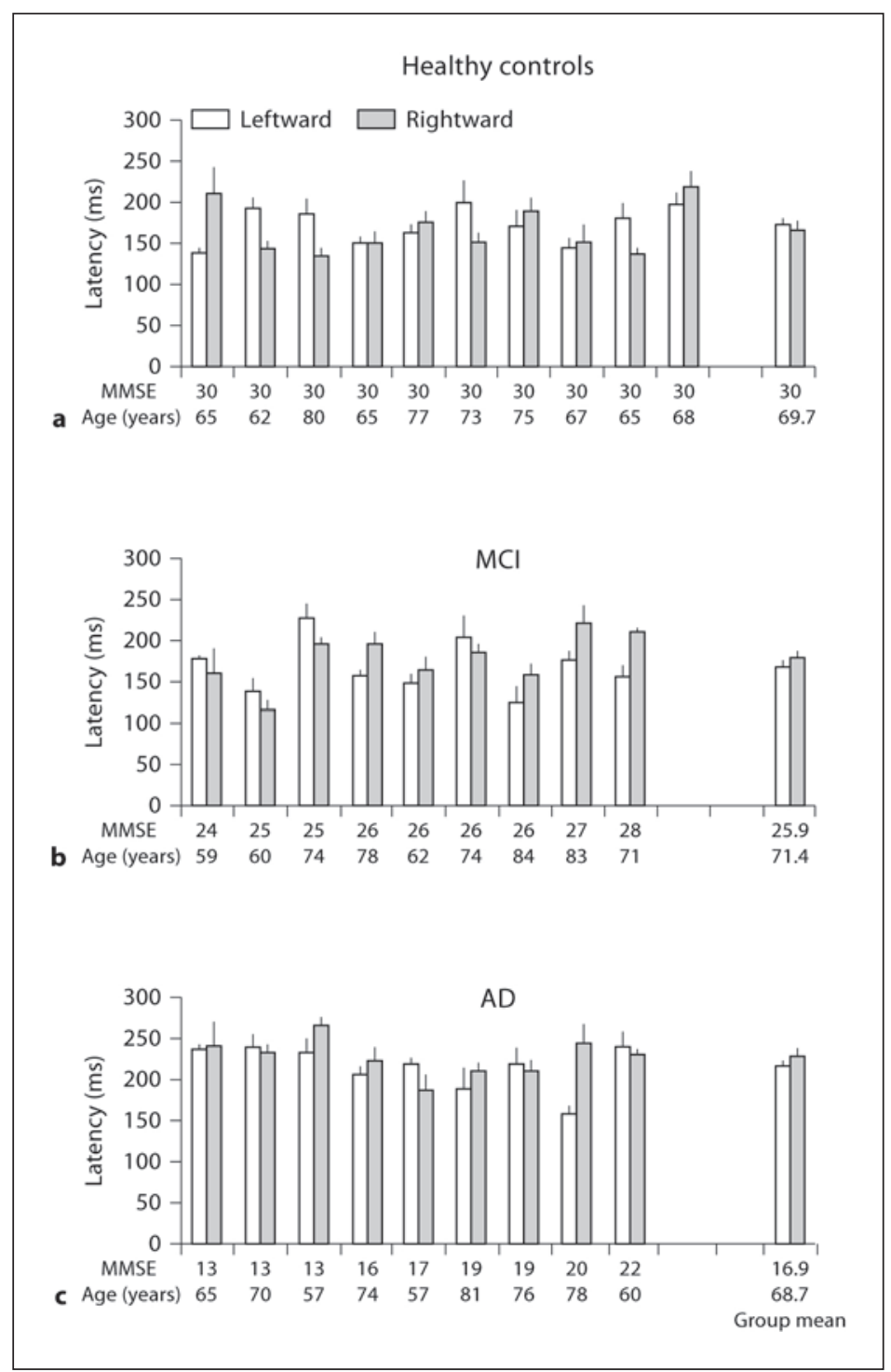

Coefficient of Variation in Saccade Latency. Figure 5 shows group mean CV in latency for leftward and rightward saccades under the gap (fig. 5a) and the overlap (fig. 5b) conditions in healthy elderly, MCI and AD subjects. The percentage of variability was relatively high (>30\%) but for all groups. The Kruskal-Wallis test showed no significant difference in $\mathrm{CV}$ in latency among the three groups for all conditions (left- and rightward gap, and leftand rightward overlap, all $\mathrm{p}>0.05$ ). Neither a direction effect (between left- and rightward, all $p>0.05$ ) nor a task effect (between gap and overlap condition, all $p>0.05$ ) was noted for $\mathrm{CV}$ in latency in three groups.

\section{Accuracy}

Gain of Saccades. Figure 6 shows group mean gains of saccades (+ SE) results for each direction in healthy elderly, MCI and AD subjects in the gap (fig. 6a) and the overlap (fig. 6b) conditions. Three-way ANOVA showed no effect of group $\left(\mathrm{F}_{2,25}=1.95, \mathrm{p}=0.16\right)$, direction $\left(\mathrm{F}_{1,25}=2.03, \mathrm{p}=0.17\right)$ and task $\left(\mathrm{F}_{1,25}=3.40, \mathrm{p}=0.08\right)$. 
Fig. 4. Individual and group mean latencies of saccades $(+\mathrm{SE})$ in the overlap task for leftward and rightward saccades in healthy elderly (a), subjects with MCI (b) and in patients with AD (c); horizontal axes represent MMSE score and age for each subject. Note: longer latencies of saccades for AD patients than for healthy elderly and MCI subjects for each direction.

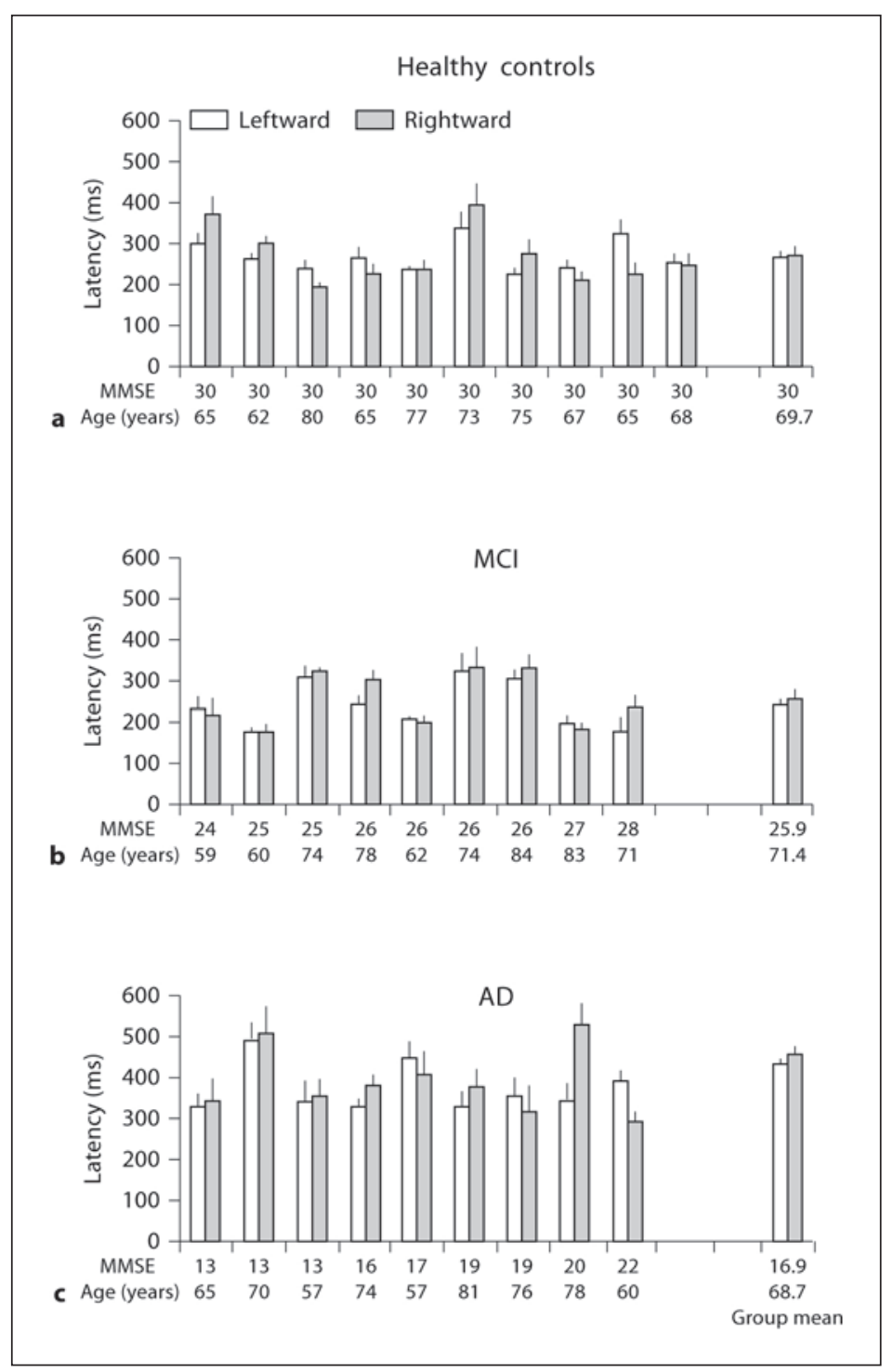

Variability in Gain. Figure 6c, d depicts group mean CV in gain for the gap and the overlap conditions, respectively. The Kruskal-Wallis test showed significant group effect in the overlap condition for leftward $(H=7.31, \mathrm{p}<0.05)$ and for rightward saccades $(\mathrm{H}=7.89, \mathrm{p}<0.05)$. Further, the Mann-Whitney $U$ test showed higher CV in gain in the overlap condition for AD subjects than for healthy elderly $(U=17, p<0.05$, for leftward and $U=16, p<0.05$, for rightward saccades) and higher $\mathrm{CV}$ for $\mathrm{AD}$ than for $\mathrm{MCI}$ subjects $(\mathrm{U}=18, \mathrm{p}<0.05$, for leftward and $\mathrm{U}=15, \mathrm{p}<0.05$, for rightward saccades). There was no group effect on the CV of gain in the gap task (neither for leftward, $\mathrm{H}=1.38, \mathrm{p}=0.5$, nor for rightward saccades, $\mathrm{H}=0.61, \mathrm{p}=0.74$ ).

\section{Speed}

Mean Velocity. Figure 7 shows group mean velocity of the saccade (+ SE) for two directions in healthy elderly, MCI and AD subjects in the gap (fig. 7a) and the overlap (fig. 7b) conditions. The three-way ANOVA showed no effect of group $\left(\mathrm{F}_{2,25}=0.38, \mathrm{p}=0.68\right)$, direction $\left(\mathrm{F}_{1,25}=0.98, \mathrm{p}=0.33\right)$ and task $\left(\mathrm{F}_{1,25}=1.59, \mathrm{p}=0.21\right)$. 
Fig. 5. Group mean CV in saccade latency in gap (a) and overlap (b) tasks for each direction in healthy elderly, MCI and AD subjects.
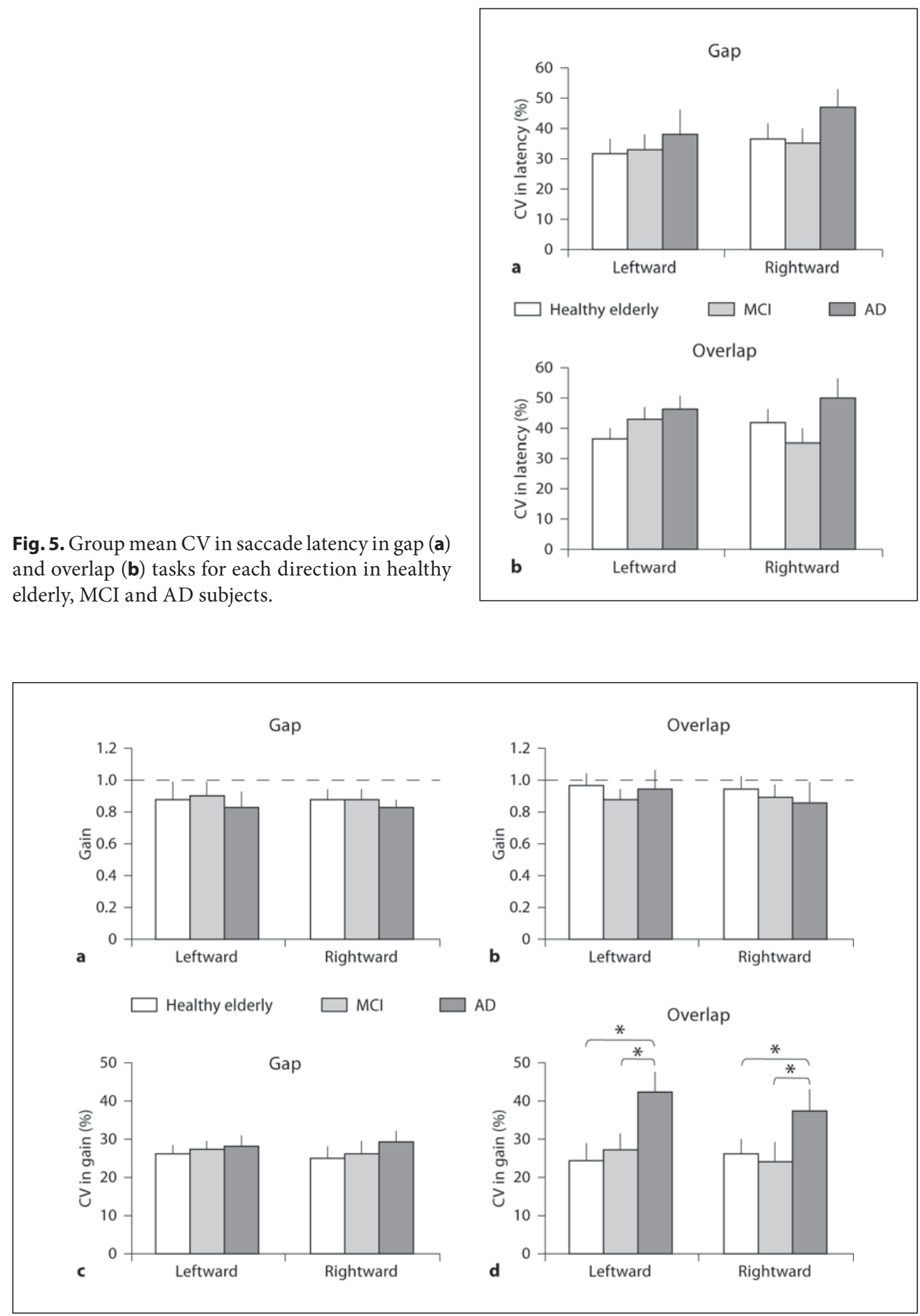

Fig. 6. Group mean gain (a, b) and group mean $\mathrm{CV}$ in gain (c, d) in gap and overlap tasks for primary saccade for each direction in healthy elderly, MCI and AD patients. Vertical lines are standard deviations and horizontal dashed lines $(\mathbf{a}, \mathbf{b})$ are gain at 1 . Note: higher $\mathrm{CV}$ in gain for $\mathrm{AD}$ patients than for healthy elderly and MCI subjects: ${ }^{*} \mathrm{p}<0.05$. 


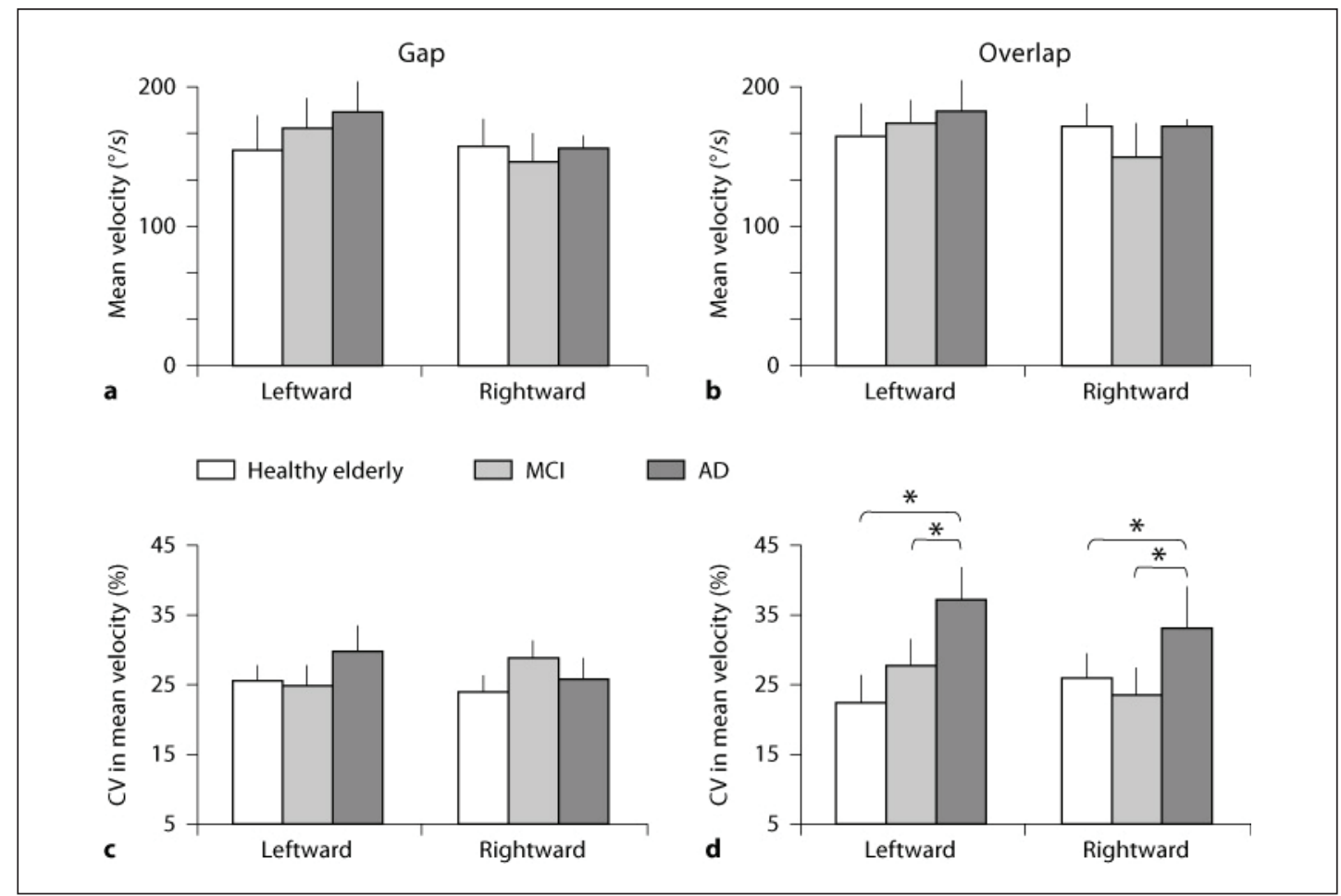

Fig. 7. Group-averaged mean velocity (a, b) and group mean CV in mean velocity gain (c, d) in gap and overlap tasks for primary saccade for each direction in healthy elderly, MCI and AD patients. Vertical lines are standard deviations. Note: higher CV in mean velocity for AD patients than for healthy elderly and MCI subjects: ${ }^{*} \mathrm{p}<0.05$.

Variability in Velocity. Figure $7 \mathrm{c}$, d illustrates group mean CV in mean velocity for the gap and the overlap conditions, respectively. The Kruskal-Wallis test showed significant group effect in the overlap condition for leftward $(\mathrm{H}=7.20, \mathrm{p}<0.05)$ and for rightward saccades $(\mathrm{H}=9.02, \mathrm{p}<0.01)$. The Mann-Whitney $\mathrm{U}$ test showed higher $\mathrm{CV}$ in mean velocity in the overlap condition for AD subjects than for healthy elderly $(U=10, p<0.01$, for leftward and $U=17, p<0.05$, for rightward saccades) and MCI subjects $(U=17, p<0.05$, for leftward and $U=14, p<0.05$, for rightward). There was no group effect of $\mathrm{CV}$ in mean velocity in the gap condition $(\mathrm{H}=0.12, \mathrm{p}=0.94$, for leftward and $\mathrm{H}=1.98, \mathrm{p}=0.37$, for rightward saccades).

\section{Discussion}

The main results are: (1) a similar gap effect (shorter latencies in gap than in overlap) exists for $\mathrm{AD}$ and $\mathrm{MCI}$ subjects as for healthy elderly; (2) abnormal long latency of saccades in gap and overlap tasks for AD compared to healthy elderly and MCI subjects; (3) accuracy of saccades (gain) and mean velocity are normal in AD an MCI subjects, and (4) variability in accuracy and speed is abnormally increased in AD patients compared with $\mathrm{MCI}$ and healthy elderly. These results will be discussed below.

Latency Deficit in $A D$

Many studies showed a normal age effect, i.e. increase in latency of saccades with age $[24,31]$. The present results concerning saccades are compatible with previous studies $[6,9$, 
11] showing that $A D$ patients with an average MMSE of 17 show longer latencies of saccades than healthy elderly. We conclude that AD patients at the moderate stage of disease show abnormal latency, and this is related to impaired function of cortical oculomotor areas, e.g. parietal and frontal areas. Dysfunction of the frontal lobe [12] and parietal cortex [30] has been noted in $\mathrm{AD}$ patients. Of note, even for healthy aged subjects versus young subjects, the increase in latency is rather attributed to cortical degeneration than to the peripheral factors $[15,31,32]$. Saccade latency increase is an indicator of cortical dysfunction. The interest here is that the MCI population shows no latency abnormality, which is in line with the absence of biological findings. Taken together, the results on AD and MCI subjects indicate the importance of applying a saccade test in the follow-up of MCI subjects. Further studies correlating MMSE scores and saccade latencies in a larger cohort are needed.

\section{Accuracy-Speed Variability in AD}

In this study, $\mathrm{AD}$ patients showed normal accuracy and mean velocity similarly to healthy elderly and MCI subjects. This result is compatible with studies of Moser et al. [11] and Garbutt et al. [9], in which AD patients had similar accuracy and velocity to normal elderly. Generally, the velocity of horizontal saccades is related to the firing frequency of the medium-lead burst neurons in the pontine paramedian reticular formation [33]. The finding of normal velocities suggests that these pontine burst units are intact in AD.

The accuracy of saccades has its complex control involving cortical-subcortical and cerebellar areas [34]. Here, the accuracy measure, gain of saccades, was not significantly different among the three groups (AD, MCI and healthy controls). In contrast to our results, Fletcher and Sharpe [8] reported significantly more hypometric saccades in patients with AD than in healthy elderly; Hotson and Steinke [17] also described that patients with senile dementia of the Alzheimer's type had a reduction in saccade accuracy. The reason for the differences in results is unknown.

In the present study, only the variability in accuracy and speed was found to be higher in $\mathrm{AD}$ patients than in healthy elderly or MCI subjects. As mentioned above, variability per se was not examined in prior studies. The statistically higher variability in the overlap condition for AD patients suggests that they were performing initial saccades out of the normal range of target execution more frequently. Therefore, this aspect of the results suggests some deficit in the estimation of the motor error signal that determines the amplitude of saccade. Perhaps, this is also related to cortical degeneration of AD. For example, neurons in the frontal [34] and parietal [34] cortex encode eye position, and some neurons in the frontal eye fields probably encode motor errors [35]. AD patients commonly have bilateral temporoparietal degeneration, which can affect the attention of a subject [36]. The greater variability in saccade accuracy and speed suggests that $\mathrm{AD}$ patients at moderate stage of disease cannot maintain accurate and rapid execution of saccades repetitively over time.

\section{Normality of MCI Subjects}

Our preliminary results indicate normal saccade latency, normal accuracy-speed parameters and normal variability for the group of MCI subjects. Although saccade latencies are the shortest reaction times, it is interesting to compare them with manual reaction times. Our results on saccade latency are consistent with other studies using simple and manual choice reaction time in cognitive tasks [2, 22, 23]. For instance, Levinoff et al. [22] reported that in MCI subjects simple and choice reaction times are $400 \pm 70$ and $598 \pm 99 \mathrm{~ms}$, respectively, which is similar to those for control subjects (403 \pm 85 and $534 \pm 96 \mathrm{~ms}$, respectively). More recent studies confirmed these results by examining simple reaction time [2, 23]. All MCI subjects had MMSE scores similar to those for control subjects, as is also the case in our study. However, when MCI subjects had significantly lower MMSE score (25.4 \pm 
$1.5)$ than elderly controls $(28.8 \pm 1.1)$, their reaction time of event-related potentials was longer during mental arithmetic calculation [37]. Further studies including larger numbers of MCI subjects with different MMSE scores are necessary to examine the possible correlation between saccade latency and MMSE. Most important, continuous follow-up of such patients is of interest. The saccade test can be useful in spotting early changes in the evolution of MCI subjects.

\section{Acknowledgments}

Experimental design and methods were conceived and developed by the IRIS group; the study was also supported by PICS CNRS (No. 4197) and the GIS-CNRS 'Vieillissement et Longévité'. Case recruitment was supported by a grant from the Shanghai Science and Technology Committee (No. 08411951100).

\section{Disclosure Statement}

There is no conflict of interest.

\section{References}

1 Kaufman LD, Pratt J, Levine B, Black SE: Antisaccades: a probe into the dorsolateral prefrontal cortex in Alzheimer's disease. A critical review. J Alzheimers Dis 2010;19:781-793.

-2 Belleville S, Bherer L, Lepage E, Chertkow H, Gauthier S: Task switching capacities in persons with Alzheimer's disease and mild cognitive impairment. Neuropsychologia 2008;46:2225-2233.

- 3 Petersen RC, Smith GE, Waring SC, Ivnik RJ, Tangalos EG, Kokmen E: Mild cognitive impairment: clinical characterization and outcome. Arch Neurol 1999;56:303-308.

4 Petersen RC, Doody R, Kurz A, Mohs RC, Morris JC, Rabins PV, et al: Current concepts in mild cognitive impairment. Arch Neurol 2001;58:1985-1992.

-5 Petersen RC: Mild cognitive impairment as a diagnostic entity. J Intern Med 2004;256:183-194.

-6 Shafiq-Antonacci R, Maruff P, Masters C, Currie J: Spectrum of saccade system function in Alzheimer disease. Arch Neurol 2003;60:1272-1278.

-7 Crawford TJ, Higham S, Renvoize T, Patel J, Dale M, Suriya A, et al: Inhibitory control of saccadic eye movements and cognitive impairment in Alzheimer's disease. Biol Psychiatry 2005;57:10521060.

8 Fletcher WA, Sharpe JA: Saccadic eye movement dysfunction in Alzheimer's disease. Ann Neurol 1986;20:464-471.

>9 Garbutt S, Matlin A, Hellmuth J, Schenk AK, Johnson JK, Rosen H, et al: Oculomotor function in frontotemporal lobar degeneration, related disorders and Alzheimer's disease. Brain 2008;131(Pt 5):1268-1281.

-10 Hershey LA, Whicker L Jr, Abel LA, Dell'Osso LF, Traccis S, Grossniklaus D: Saccadic latency measurements in dementia. Arch Neurol 1983;40:592-593.

-11 Moser A, Kompf D, Olschinka J: Eye movement dysfunction in dementia of the Alzheimer type. Dementia 1995;6:264-268.

-12 Boxer AL, Geschwind MD, Belfor N, Gorno-Tempini ML, Schauer GF, Miller BL, et al: Patterns of brain atrophy that differentiate corticobasal degeneration syndrome from progressive supranuclear palsy. Arch Neurol 2006;63:81-86.

-13 Mosimann UP, Muri RM, Burn DJ, Felblinger J, O’Brien JT, McKeith IG: Saccadic eye movement changes in Parkinson's disease dementia and dementia with Lewy bodies. Brain 2005;128(Pt 6):12671276 . 
-14 Abel LA, Unverzagt F, Yee RD: Effects of stimulus predictability and interstimulus gap on saccades in Alzheimer's disease. Dement Geriatr Cogn Disord 2002;13:235-243.

$\checkmark 15$ Kapoula Z, Yang Q, Vernet M, Dieudonne B, Greffard S, Verny M: Spread deficits in initiation, speed and accuracy of horizontal and vertical automatic saccades in dementia with Lewy bodies. Front Neurol 2010;1:138.

-16 Blekher T, Johnson SA, Marshall J, White K, Hui S, Weaver M, et al: Saccades in presymptomatic and early stages of Huntington disease. Neurology 2006;67:394-399.

- 17 Hotson JR, Steinke GW: Vertical and horizontal saccades in aging and dementia. J Neuroophthalmol 1988;8:267-273.

- 18 Tedeschi G, Di Costanzo A, Allocca S, Quattrone A, Casucci G, Russo L, et al: Age-dependent changes in visually guided saccadic eye movements. Funct Neurol 1989;4:363-367.

-19 Sharpe JA, Zackon DH: Senescent saccades. Effects of aging on their accuracy, latency and velocity. Acta Otolaryngol 1987;104:422-428.

-20 Munoz DP, Broughton JR, Goldring JE, Armstrong IT: Age-related performance of human subjects on saccadic eye movement tasks. Exp Brain Res 1998;121:391-400.

-21 Yang Q, Kapoula Z: Aging does not affect the accuracy of vertical saccades nor the quality of their binocular coordination: a study of a special elderly group. Neurobiol Aging 2008;29:622-638.

-22 Levinoff EJ, Saumier D, Chertkow H: Focused attention deficits in patients with Alzheimer's disease and mild cognitive impairment. Brain Cogn 2005;57:127-130.

23 Sylvain-Roy S, Bherer L, Belleville S: Contribution of temporal preparation and processing speed to simple reaction time in persons with Alzheimer's disease and mild cognitive impairment. Brain Cogn 2010;74:255-261.

-24 van Deursen JA, Vuurman EF, Smits LL, Verhey FR, Riedel WJ: Response speed, contingent negative variation and P300 in Alzheimer's disease and MCI. Brain Cogn 2009;69:592-599.

-25 Dubois B, Feldman HH, Jacova C, Cummings JL, Dekosky ST, Barberger-Gateau P, et al: Revising the definition of Alzheimer's disease: a new lexicon. Lancet Neurol 2010;9:1118-1127.

-26 Dubois B, Feldman HH, Jacova C, Dekosky ST, Barberger-Gateau P, Cummings J, et al: Research criteria for the diagnosis of Alzheimer's disease: revising the NINCDS-ADRDA criteria. Lancet Neurol 2007;6:734-746.

-27 Folstein MF, Folstein SE, McHugh PR: 'Mini-mental state'. A practical method for grading the cognitive state of patients for the clinician. J Psychiatr Res 1975;12:189-198.

28 van Beers RJ: The sources of variability in saccadic eye movements. J Neurosci 2007;27:8757-8770.

-29 Peltsch A, Hemraj A, Garcia A, Munoz DP: Age-related trends in saccade characteristics among the elderly. Neurobiol Aging 2011;32:669-679.

- 30 Brun A, Englund E: Regional pattern of degeneration in Alzheimer's disease: neuronal loss and histopathological grading. Histopathology 1981;5:549-564.

-31 Yang Q, Kapoula Z, Debay E, Coubard O, Orssaud C, Samson M: Prolongation of latency of horizontal saccades in elderly is distance and task specific. Vision Res 2006;46:751-759.

-32 Yang Q, Kapoula Z: The control of vertical saccades in aged subjects. Exp Brain Res 2006;171:67-77.

33 Leigh RJ, Zee DS: The Neurology of Eye Movements, ed 4. New York, University Press, 2006.

-34 Van Gisbergen JA, Robinson DA, Gielen S: A quantitative analysis of generation of saccadic eye movements by burst neurons. J Neurophysiol 1981;45:417-442.

35 Goldberg ME, Bruce CJ: Frontal eye fields in the monkey: eye movements remap the effective coordinates of visual stimuli. Soc Neurosci 1981;7:131.

- 36 Kim EJ, Lee BH, Seo SW, Moon SY, Jung DS, Park KH, et al: Attentional distractibility by optokinetic stimulation in Alzheimer disease. Neurology 2007;69:1105-1112.

37 Li Y, Wang YP, Wu G, Shi F, Zhou LP, Lin WL, et al: Discriminant analysis of longitudinal cortical thickness changes in Alzheimer's disease using dynamic and network features. Neurobiology 2011, E-pub ahead of print. 